\title{
Utilization of Oil and Coal Industrial Waste by Combustion in the Form of Slurry and Granulate
}

\author{
Pavel Strizhak $^{1}$, Ksenia Vershinina ${ }^{1}$, Daniil Romanov ${ }^{1}, \operatorname{Vadim}$ Dorokhov $^{1}$ \\ ${ }^{1}$ National Research Tomsk Polytechnic University \\ Lenina Avenue, 30, Tomsk, Russia, 634050 \\ vershininaks@tpu.ru
}

\begin{abstract}
A lot of industrial waste is generated annually throughout the world. The extractive and processing industries are traditional leaders in the field of waste generation. According to the minimum estimates, several hundred million tons of coal processing and refining wastes are generated every year in the world. More than 2 billion tons of these wastes have already been accumulated. An important global goal is the effective, large-scale and safe recycling of industrial wastes. One of the ways to achieve this goal is to develop useful technologies of combustion of industrial wastes as composite fuels. Fuels prepared on the basis of coal processing waste, rapeseed oil, used turbine oil were considered in this study. We tested three forms of waste derived fuels: slurry, dried slurry (after storage) and granulate. Energy, environmental, economic aspects of the use of these fuels were under study. We determined the time and temperature parameters of ignition and combustion of the tested fuels using a laboratory muffle furnace $\left(\right.$ at $\left.350-1000{ }^{\circ} \mathrm{C}\right)$. The concentrations of dangerous sulphur and nitrogen oxides, contained in combustion products, were also measured. It was established that the granulated fuels have minimum ignition temperatures and ignition delay times (50-80\% lower than for the slurry and dried slurry). However, the combustion of waste derived slurries is characterized by minimum concentrations of $\mathrm{NO}_{\mathrm{x}}$ and $\mathrm{SO}_{\mathrm{x}}$ (by $18-75 \%$ lower than in the granulated state). Taking into account the cost, we calculated the efficiency of the tested fuels in comparison with traditional coal. According to the integral relative parameters, the use of waste-derived slurries is most attractive. The results of the research can be used in the thermal engineering to develop efficient (by energy, environmental and economic parameters) heat and power generation technologies by combustion of composite fuels derived from industrial waste.
\end{abstract}

Keywords: industrial waste; waste-derived fuel; ignition; combustion; emission; droplet; granulate; slurry

\section{Introduction}

The striking amounts of industrial waste as a result of its formation and accumulation are of great concern. In many countries, industrial waste recycling practices are weak. However, most industrial wastes can be recycled or reused. A large group of industrial waste is a potential fuel, but as such often remains abandoned. This group includes coal waste (waste of flotation and gravity enrichment, various slimes), as well as waste of oil origin (for example, waste oil, water-oil emulsion, oil sludge). Their conversion, processing for the purpose of repeated targeted use is possible, but very costly $[1,2]$. The amount of waste is constantly growing. In particular, waste coal is at least 10-15\% of the mass of processed (mine) coal. According to the known production volumes [3], more than 1 billion tons of coal wastes are formed annually. Oil industry waste is generated very quickly and in large scales. Today, more than 1 billion tons of oil sludge and over 150 million tons of petroleum products (including oils, oil liquids, etc.) are produced annually [4-6]. The utilization of waste by incineration is of interest. It is also possible to involve additional components (including solid and liquid waste from manufacturing and processing enterprises of all kinds), which allow obtain composite fuels with new technological, ecological and energy properties, while simultaneously disposing of unclaimed industrial wastes.

Today, the problems of co-combustion of coal and biomass are being intensively studied [7,8]. There is also the experience of burning a coal granulate obtained after the addition of oil sludge, oil refinery waste, used industrial and household oils $[1,9]$. The novelty of this paper is that for the first time, we will analyze both energy and environmental parameters of ignition and burning of coal processing waste, used petroleum oil and vegetable oil during combustion in the form of a granulate, a droplet of slurry and jelly-like particle. All this components, unfortunately, are still poorly involved in the fuel and energy cycle. 


\section{Materials}

In this work, the following components were used to prepare fuels: coal flotation waste (filter-cake), used turbine oil, rapeseed oil. The use of oils of different origins in one experimental study makes it possible to analyse quite clearly the significance of oil origin factor (in terms of the scale of the change in the ignition and combustion characteristics). Tables 1 and 2 illustrate the basic properties of the components. The properties of the filter cake (Table 1) are given for the dry or dry ash-free state. In its original form (after coal-washing plant), the filter cake represents a wet mass with a water content of about $43.5 \%$ and a combustion heat of about $16.4 \mathrm{MJ} / \mathrm{kg}$.

Table 1: Results obtained from proximate and ultimate analysis of filter cake of nonbaking coal in dry state.

\begin{tabular}{|c|c|c|c|c|c|c|c|}
\hline \multicolumn{3}{|c|}{ Proximate analysis } & \multicolumn{5}{c|}{ Ultimate analysis $(\%)$} \\
\hline $\mathrm{A}^{\mathrm{d}}(\%)$ & $\mathrm{V}^{\text {daf }}(\%)$ & $\mathrm{Q}^{\mathrm{a}}{ }_{\mathrm{s}}(\mathrm{MJ} / \mathrm{kg})$ & $\mathrm{C}^{\mathrm{daf}}$ & $\mathrm{H}^{\mathrm{daf}}$ & $\mathrm{N}^{\text {daf }}$ & $\mathrm{S}_{\mathrm{t}}{ }^{\mathrm{d}}$ & $\mathrm{O}^{\text {daf }}$ \\
\hline 21.2 & 16.09 & 26.92 & 90.13 & 4.255 & 2.31 & 0.441 & 2.77 \\
\hline
\end{tabular}

Table 2: Properties of oils.

\begin{tabular}{|c|c|c|c|c|c|c|}
\hline Sample & $\begin{array}{c}\text { Density at } \\
20{ }^{\circ} \mathrm{C}\left(\mathrm{kg} / \mathrm{m}^{3}\right)\end{array}$ & $\begin{array}{c}\text { Humidit } \\
\mathrm{y}(\%)\end{array}$ & $\begin{array}{c}\text { Ash } \\
(\%)\end{array}$ & $\begin{array}{c}\text { Flash point } \\
\left({ }^{\circ} \mathrm{C}\right)\end{array}$ & $\begin{array}{c}\text { Temperature } \\
\text { of ignition } \\
\left({ }^{\circ} \mathrm{C}\right)\end{array}$ & $\begin{array}{c}\text { Heat of } \\
\text { combustion }(\mathrm{MJ} / \mathrm{kg})\end{array}$ \\
\hline Used turbine oil & 868 & - & 0.03 & 175 & 193 & 44.99 \\
\hline Rapeseed oil & 911 & 0.28 & 0.03 & 242 & - & 39.52 \\
\hline
\end{tabular}

Two types of slurries were made: (1) $80 \%$ wet filter cake, $20 \%$ used turbine oil; (2) $80 \%$ wet filter cake, $20 \%$ rapeseed oil. Fuel of this type can be burned in the form of a droplet aerosol due to the high content of liquid components (oil, water). The prepared slurries were the first type of studied fuels. At the second stage, the slurries were held in a sealed container for three days (72 hours). During this time interval, under the influence of gravity, the solid particles of the filter cake began to settle. A moisture layer was formed on the surface of the fuel and was removed. The precipitate (dried fuel or gel) was the second type of fuel under study. The third type of fuel is represented by the so-called granulate. Special samples from the jelly-like fuel (second type) were formed in the form of granules about of $2 \mathrm{~mm}$ in size (to study ignition characteristics) and $20 \mathrm{~mm}$ (for recording the emission characteristics of combustion). Subsequently, the fuel granulate was aged by open storage for 24 hours at a temperature of $20^{\circ} \mathrm{C}$, a pressure of $101.3 \mathrm{kPa}$ and a relative humidity of $80 \%$ (laboratory conditions).

\section{Experimental Setup and Methods}

A muffle tube furnace (model combustion chamber) was used for the combustion of fuel samples. A detailed description of the experimental setup, procedure, measuring devices and errors is given in [10, 11]. The heating temperature was varied from $350{ }^{\circ} \mathrm{C}$ to $1000{ }^{\circ} \mathrm{C}$. A coordinate mechanism was used for the automated placement of a fuel sample into the combustion chamber. A sample (slurry drop, jelly-like fuel, granulate) was placed on a holder (thermocouple junction). The video camera was used to record the whole process of fuel heating and burning. The size (initial radius) of droplets and fuel particles in the study was about $2 \mathrm{~mm}$. To determine this parameter, a frame with a drop (particle) image was saved before entering the combustion chamber. Using the Tema Automotive software package, the size of the droplet (particle) in the four sections was measured from the initial image.

In this study we measured ignition delay times $\left(\tau_{d}\right)$; minimum ignition temperatures $\left(T_{g}{ }^{\mathrm{min}}\right)$ for each fuel sample. The time characteristics of the ignition were determined by the fuel luminosity in accordance with the procedure described in $[10,11]$. This procedure is based on the comparison of the luminosity of the fuel sample during the reaction with the reference values obtained using high-precision and low-inertia thermocouples. 
Concentrations of the sulfur and nitrogen oxides were chosen as parameters characterizing the environmental parameters of fuel combustion. The registration of gaseous emission concentrations was carried out using gas analyzing system [12]. The flue gases formed during the fuel combustion were flowed along the gas sampling hose to the electrochemical sensors of the gas analyzer. Continuous monitoring and recording of flue gas components was carried out using specialized EasyEmisson software [12].

\section{Results and Discussion}

Fig. 1 illustrates the experimental values of time delays of heterogeneous stable ignition of droplets and particles of the investigated fuels: waste-derived slurries, jelly slurries (after 72 hours of storage) and granulates. Of course, the humidity is the main determining factor that affects the ignition of the tested fuels. Three states of the same fuel (by the components) have a different moisture share. Therefore, the greatest ignition inertia is characterized by more humid fuels - initial slurries in the liquid state. With a decrease in the moisture content of the fuel, the ignition delay times decrease. Therefore, the granulates are characterized by small ignition inertia (Fig. 1). This type of fuel ignites lighter than the original wet fuels. The maximum differences in the delay time for the ignition of the slurry and the granulate are on the average 60-80\%. These differences are most noticeable in the low temperature region in the combustion chamber and decrease with increasing temperature of the external gaseous medium (Fig. 1).

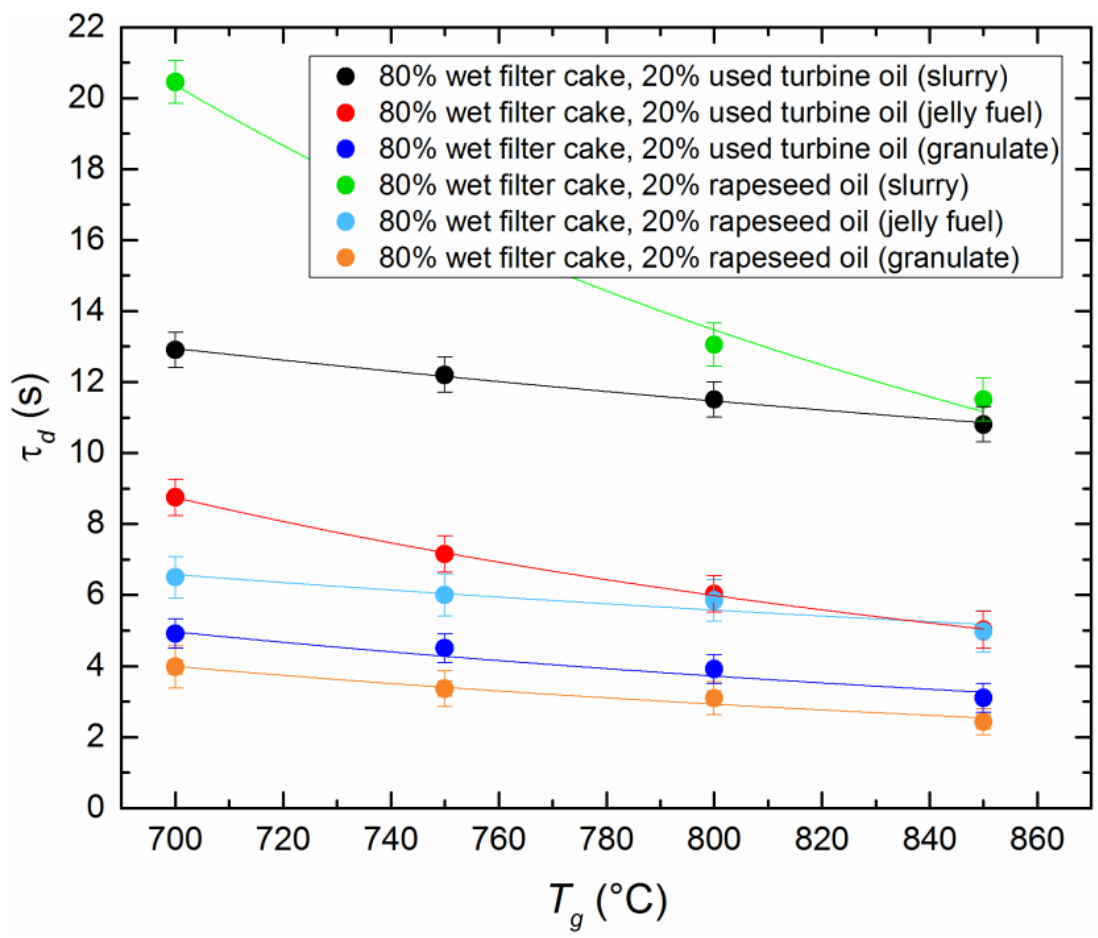

Fig. 1: Effect of the temperature in the combustion chamber on the fuel ignition delay time.

The threshold temperatures required for stable combustion initiation of the investigated fuels were varied in the range of 390-445 ${ }^{\circ} \mathrm{C}$ (Table 3) and as the fuel humidity was decreased, the ignition temperature was decreased. This parameter was maximally different for the wettest fuel (initial slurry) and the driest fuel (granulate). The maximum difference was about $40{ }^{\circ} \mathrm{C}$. At high humidity, the proportion of combustible mass in the fuel is lowered. Under such conditions, the concentration of volatile products of decomposition of coal and oil vapors is not sufficient to realize the ignition conditions $[11,13]$. In addition, a large amount of heat is consumed on endothermic water evaporation. It is necessary to raise the temperature in the combustion chamber to fulfill the conditions for ignition of the fuel components. 
The values of the highest calorific value of the tested fuels are shown in Table 3. These values are obtained additively, based on the mass fraction and the heat of combustion of each individual component of the fuel. It is possible to assess the prospects of a particular fuel, in terms of its potential heating value when burning in boiler plants. Undoubtedly, the most attractive fuel for this criterion is granulates with petroleum oil. However, wet slurries are also characterized by sufficiently high heat of combustion, which illustrates their attractiveness for combustion.

The decrease in the heating value of the waste-derived mixture will be facilitated by: (i) an increase in the mass fraction of inert moisture; (ii) a decrease in the proportion of the liquid fuel component; (iii) the use of vegetable oils (because petroleum liquids, especially oils, have a higher calorific value). However, fuel combustion should be considered not only from the energy point of view. It is necessary to take into account technological, economic and environmental aspects. Therefore, the goal of creating a fuel composition cannot be only to maximize the calorific value and minimize the costs of ignition. It is important to take into account that with increasing heat of combustion the heat stresses of heating surfaces increase, and also the concentrations of anthropogenic emissions increase potentially.

Table 3: Minimum ignition temperature and high combustion heat of the studied fuels.

\begin{tabular}{|c|c|c|c|c|c|c|}
\hline \multirow{2}{*}{ Parameter } & \multicolumn{2}{|c|}{$80 \%$ wet filter cake, 20\% used turbine oil } & \multicolumn{3}{c|}{$80 \%$ wet filter cake, 20\% rapeseed oil } \\
\cline { 2 - 7 } & Slurry fuel & Dried (jelly) fuel & Granulated fuel & Slurry fuel & Dried (jelly) fuel & Granulated fuel \\
\hline$T_{g}{ }_{g}{ }^{\text {in }},{ }^{\circ} \mathrm{C}$ & 440 & 430 & 400 & 430 & 420 & 390 \\
\hline$Q^{a}{ }_{s}, \mathrm{MJ} / \mathrm{kg}$ & 22.10 & 22.40 & 23.20 & 21.05 & 21.45 & 23.05 \\
\hline
\end{tabular}

Fig. 2 shows the concentrations of the main anthropogenic emissions $\left(\mathrm{SO}_{\mathrm{x}}, \mathrm{NO}_{\mathrm{x}}\right)$ produced by burning the tested fuels in three aggregate states (liquid, jelly and granular). As the moisture share decreases, $\mathrm{SO}_{\mathrm{x}}$ emissions can increase to $65 \%$ and $\mathrm{NO}_{\mathrm{x}}$ to $75 \%$. This result is due to the significant influence of the water concentration on the composition of the combustion products. Water, as a carrier medium for slurry, reduces the temperature and speed of adiabatic combustion, which leads to a reduction in $\mathrm{NO}_{\mathrm{x}}$ formation. In addition, the decomposition of water, caused by heating, leads to the release of free molecules of oxygen and hydrogen. The oxygen formed during the reaction intensifies the combustion process, and hydrogen acts as a reducing agent, contributing to a reduction in the nitrogen and sulphur oxides in the flue gases. Removing most of the moisture to produce granules leads to a regular increase in temperature in the combustion zone, which intensifies the mechanism of oxidation of nitrogen and sulphur contained in the fuel to the corresponding oxides. In experiments with turbine oil, it has been found that the concentrations of sulphur oxides for fuels in slurry and gel state are higher than in compositions with rapeseed oil (Fig. 2). This fact is due to the chemical composition of the used oils. The sulphur content of turbine oils is usually in the range of $0.5-1.1 \%$, sulphur content in rapeseed oil does not exceed $0.03 \%$. However, from the point of view of nitrogen oxides, the difference in values with variation of the oil type is not significant for all three considered fuel states (Fig. 2). This is due to the fact that the emission of nitrogen oxides is more affected by the temperature regime of combustion. The high calorific value of rapeseed and used turbine oils leads to a significant increase of temperature in the combustion zone. An additional heat release leads to a high-temperature mechanism of nitrogen oxidation in the combustion zone when high temperatures (over $1000{ }^{\circ} \mathrm{C}$ ) are reached.

In accordance with the approach [14], we evaluated the effectiveness of the tested fuels compared with traditional coal dust. The calculated coefficients take into account the heat of combustion, the fuel cost, as well as the environmental parameters ( $\mathrm{SO}_{\mathrm{x}}$ and $\mathrm{NO}_{\mathrm{x}}$ concentrations in the combustion products). Fig. 3 shows the results of calculation. Efficiency coefficient equal to 1 corresponds to coal (red line in Fig. 3).

It can be concluded that fuels with the addition of used turbine oil are the most attractive in terms of the considered parameters (Fig. 3). As moisture decreases, the coefficient is declines, mainly due to the deterioration of the environmental performance of combustion. However, even in the form of granulate, fuel particles based on coal washing and oil refining waste are 4.5-11.3 times more efficient than coal dust (Fig. 3). 

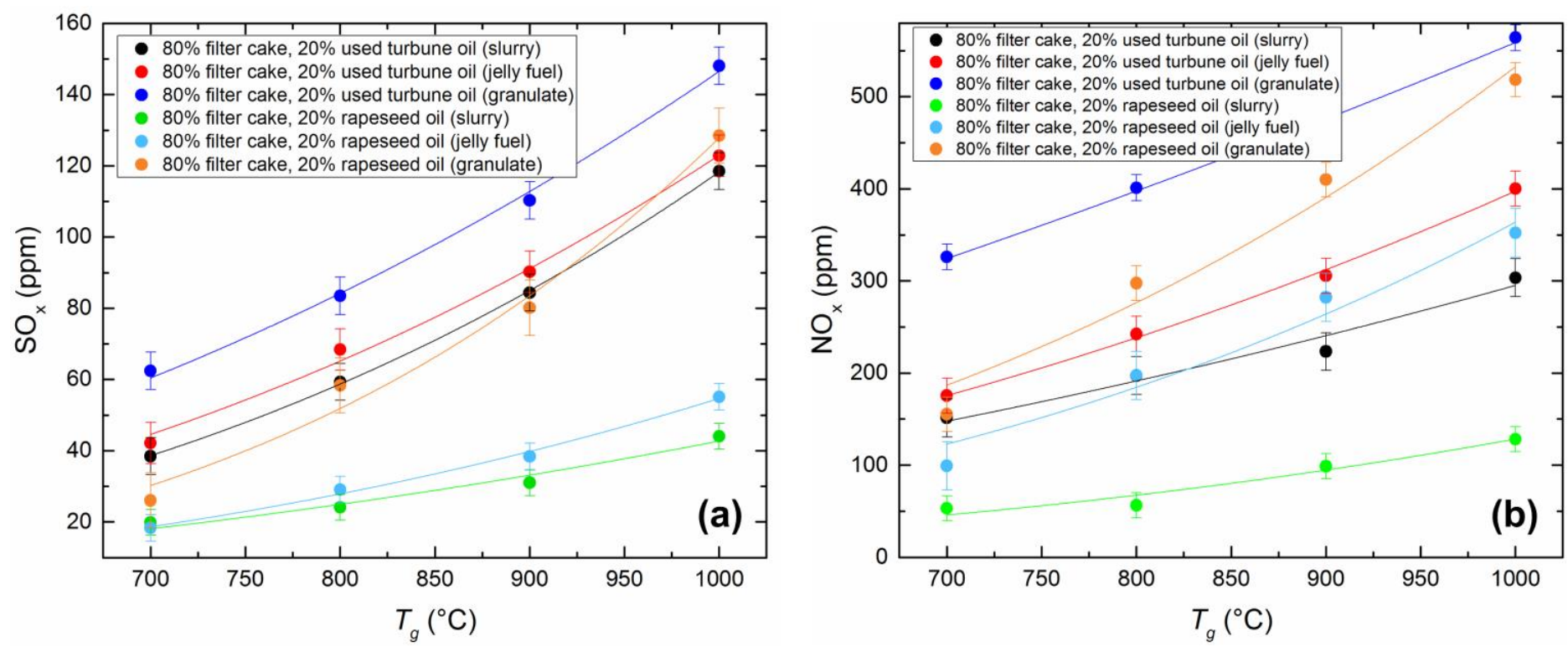

Fig. 2: Concentrations of emissions of sulfur oxides (a) and nitrogen oxides (b) in combustion products of fuels versus temperature in the combustion chamber.

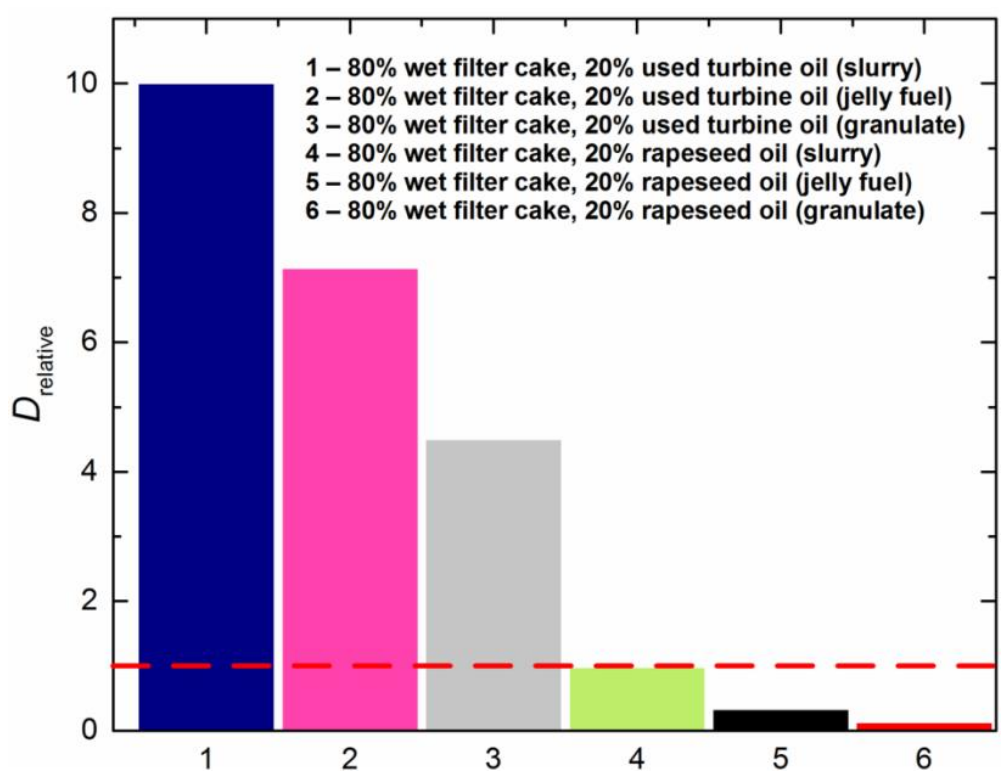

Fig. 3: The relative efficiency of waste-derived fuels in comparison with bituminous coal dust.

Jelly-like and solid fuels with the addition of rapeseed oil lose relative to coal by more than 9 times $\left(D_{\text {relative }}\right.$ are ranged from 0.11 to 0.74 ). Sufficiently low coefficients (Fig. 3) are mainly due to the fact that the cost of vegetable oils is several times higher than the cost of petroleum waste components. For example, the average market price of rapeseed oil is about $0.8 \$ / \mathrm{kg}$, and the cost of used turbine oil is about $0.09 \$ / \mathrm{kg}$. However, the use of rapeseed oil in the fuel composition instead of petroleum ones makes it possible to increase the energy performance (ignition temperature, burning rate, ignition delay and full burning) without increasing the environmental damage in the case of burning slurry fuel. 


\section{Conclusion}

By-products and waste of coal washing and oil refining can be effectively burned in a liquid (slurry), jelly and state. Minimum ignition delay times and ignition temperatures are achieved in a granular state. In the liquid slurry state, minimal concentrations of $\mathrm{NO}_{\mathrm{x}}$ and $\mathrm{SO}_{\mathrm{x}}$ emission are ensured. The use of rapeseed oil instead of petroleum product can improve the environmental parameters of fuel combustion in the form of aqueous slurry.

As a result of the experimental studies performed, the ranges of changes in the basic parameters of ignition and combustion of waste-derived fuels were determined. It is convenient to use sufficiently wide ranges of changes in the parameters and conditions of combustion in the adaptation (development) of promising technologies for the burning of waste-derived fuels satisfying the required environmental, economic and environmental performance indicators.

The results of the experiments are important for the development of power engineering in countries with dominant sectors of the coal, oil and gas industry, which have large amounts of accumulated waste annually. The use of waste as combustible components of composite fuels will solve the problem of waste disposal, expanding the fuel base for energy generation and reducing the rate of mining of fossil fuels.

\section{Acknowledgements}

This study was supported by the Russian Science Foundation (project No. 18-73-00013).

\section{References}

[1] M. F. Demirbas, "Progress of fossil fuel science," Energy Sources Econ Plann Policy, vol. 2, no. 3, pp. 243-257, 2007.

[2] Q. Zhang, J. Hu, D. Lee, Y. Chang, Y. Lee, "Sludge treatment: Current research trends," Bioresour. Technol., vol. 243, pp.1159-1172, 2017.

[3] Key World Energy Statistics. 2017. International Energy Agency.

[4] Global Waste Management Outlook. United Nations Environment Programme. 2015.

[5] N. Lior, "Energy resources and use: the present situation and possible paths to the future," Energy, vol. 33, pp. 842-857, 2008.

[6] V. V. Ermakov, A. Bogomolov, D. E. Bykov, "Oil sludge depository assessment using multivariate data analysis," J Environ Manage, vol. 105, pp. 144-151, 2012.

[7] A. A. Bhuiyan, A. S. Blicblau, A. K. M. Sadrul Islam, J. Naser, "A review on thermo-chemical characteristics of coal/biomass co-firing in industrial furnace," J. Energy Inst., vol. 91, no. 1, pp. 1-18, 2018.

[8] L. Baxter, "Biomass-coal co-combustion: opportunity for affordable renewable energy," Fuel, vol. 84, pp. 1295-1302, 2005.

[9] Q. Zhang, J. Hu, D. Lee, Y. Chang, Y. Lee, "Sludge treatment: Current research trends," Bioresour Technol, vol. 243, pp. 1159-1172, 2017.

[10] K. Y. Vershinina, N. E. Shlegel, P. A. Strizhak, "Influence of the initial temperature of coal water slurries containing petrochemicals on their ignition characteristics," Appl. Therm. Eng., vol. 138, pp. 591-602, 2018.

[11] G. V. Kuznetsov, K. Y. Vershinina, T. R. Valiullin, P. A. Strizhak, "Differences in ignition and combustion characteristics of waste-derived oil-water emulsions and coal-water slurries containing petrochemicals," Fuel Process Technol., vol. 179, pp. 407-421, 2018.

[12] G. S. Nyashina, K. Y. Vershinina, M. A. Dmitrienko, P. A. Strizhak, "Environmental benefits and drawbacks of composite fuels based on industrial wastes and different ranks of coal," J. Hazard Mater., vol. 347, pp. 359-370, 2018.

[13] A. Kijo-Kleczkowska, "Combustion of coal-water suspensions," Fuel, vol. 90, pp. 865-877, 2011.

[14] M. A. Dmitrienko, G. S. Nyashina, P. A. Strizhak, "Major gas emissions from combustion of slurry fuels based on coal, coal waste, and coal derivatives," J. Clean Prod., vol. 177, pp. 284-301, 2018. 